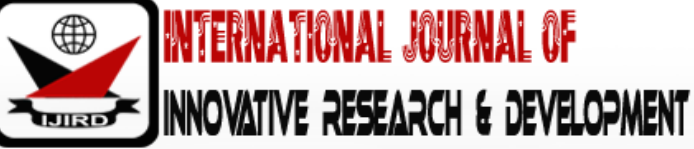

ISSN 2278 - 0211 (Online)

\section{The Role and Use of ICT in Administrative Activities in Higher Education Institutions: The Views of Administrators in Higher Educational Institutions in Ghana}

\author{
Rosemary Seiwah Bosu \\ Institute for Educational Planning and Administration, \\ University of Cape Coast, Ghana
}

\begin{abstract}
:
With the ongoing reforms in the Ghanaian education system, Information and Communication Technology (ICT) is increasingly being promoted to improve quality education. It has become apparent that reform in higher education cannot succeed effectively without paying attention to ICTs, particularly applications in education management and administration and having access to knowledge in support of teaching, research, and lifelong learning $($ Adam,2003). In order to promote the usage of ICT in teaching and learning, it is important that administrators are committed to supporting its use as well as use it themselves. Since the 21st century has witnessed rapid advancements in technology leading to far-reaching developments in the administrative system (Meenakumari \& Krishnaveni 2011), recognising the importance of ICT by administrators is critical to promoting its use by all stakeholders in the education system. This study used an exploratory approach to find out the perceptions of administrators in higher education institutions (HEIs) to the role and importance they attach to the use of ICT for administrative activities. Four HEIs were randomly selected and 18 administrators selected using purposive sampling were interviewed. The findings revealed that the use of ICT has fundamentally changed the majority of administrative practices and procedures. The administrators agreed that technology is an essential part of their work that it played a critical role in impacting positively on the quality of administrators work. It was recommended that HEIs need to continually create the awareness of the benefits of ICT use, adopt strategic plans committed to ICT integration, provide adequate training based on identified needs as well as provide the needed ICT tools and facilities.
\end{abstract}

Keywords: Higher education, information and communication technology, administration, administrator

\section{Introduction}

The use of Information and Communication Technology (ICT) for administrative activities is becoming increasingly significant in higher education institutions today. ICT within this context refers to technologies such as computers, mobile phones, projectors and radio. They are a diverse set of technological tools and resources used to communicate, to create, disseminate, store and manage information (Toro \& Joshi, 2012). Administration, according to Hornby (as cited in Onyije \& Opara, 2013), is perceived as the set of activities done in order to plan, organise and successfully run a business, school or other institution, a process or act of organizing the way that something is done. These activities are essential for the smooth running of teaching and learning in educational institutions. The integration of ICT in administrators work can support their activities since, as Onije and Opara (2013) noted, ICT includes facilities, tools or resources that could be used to process, store, preserve, access, retrieve and disseminate information with ease. Alam (2016) also indicated that "ICT in administration of educational institutions plays a major role in the efficient utilization of existing resources and simplifies the administration tasks (e.g. in student administration, staff administration and general administration) by reducing the paper work and replacing the manual maintenance of record keeping to electronic maintenance of records which helps in easy retrieval of any information of students, staff and general within a fraction of seconds can access the required information"(p164). Similarly, Onyije and Opara (2013) noted that the role of ICT in institutional administration is to organise information, compute and process paper work, enhance communication and planning, improve monitoring and manage teaching and learning activities. Administrators' activities in the present information age and the increase in human and physical resources become more effective and efficient with the use of ICT. Likewise, the 21st century has witnessed rapid advancements in technology which has led to far-reaching developments in the administrative system (Meenakumari \& Krishnaveni, 2011).

Technology use by administrators in this context primarily refers to the use of computers to access information, communicate, support instruction and assist in the accomplishment of administrative and managerial tasks in educational institutions (Bosu, 2008). The role of technology in administration of higher education institutions therefore cannot be overemphasized, that is why administrators need to be aware of it, understand how it can support their activities and have 
a positive attitude towards its use. This paper focuses on and explores the role of ICT in higher education institutions and its application to administrative activities from the perspective of administrators.

\section{Literature Review}

\subsection{Higher Education in Ghana}

Higher Education in Ghana (also referred to as tertiary education) within the context of this study refers to postsecondary education provided in universities, specialist institutions, technical universities, polytechnics, colleges of education and nursing training colleges and any other institutions that offer post-secondary academic and professional education or training leading to the award of diploma and degree qualifications. Presently, according to the National Accreditation Board (www.nab.gov.gh ) tertiary educational institutions in Ghana include ten public universities, 81 accredited private institutions, eight technical universities, two polytechnics, 39 public colleges of education, seven private colleges of education, 25 public nursing training colleges and 13 private nursing training colleges. Newman (2016), noted that enrolment in Ghanaian higher education institutions continues to increase; for instance, from 2011 to 2015 enrolments (regular students) in tertiary education increased by nearly 30\%. In Africa, massification of higher education has occurred mainly because of improvement at primary and secondary education levels, resulting in a large cohort of graduates seeking access to higher education, and also the realisation now that higher education is crucially important for economic development (Mohamedbhai, 2008).

Having more students and staff means the management and administration activities in these institutions become more complex leading to the change in practice with the increasing use of technology to support activities. These higher education institutions are working towards ensuring that administrative activities are adopting technology to provide modernized support services that promote success in education. This is important for higher education institutions in Ghana because as it was concluded from a study conducted on the effects of massification on higher education in Africa, ICT can enhance the effectiveness and efficiency of many of the operations of higher education institutions and overcome some of the constraints posed by massification (Mohamedbhai, 2008).

\subsection{ICT Resources for Administrative Activities in Higher Education}

Information and Communication Technology plays a vital role in supporting powerful, efficient management and administration in the education sector (Meenakumari \& Krishnaveni 2011). Its inherent attributes such as accuracy, high speed performance, reliability and capability to store very large amount of data have made it possible for its applicability to administrative activities. ICT resources are therefore critical for improving these activities. Technology can be used right from student administration to various other aspects of resource administration in an education institution (Maki, 2008). However, the majority of higher education institutions in Africa have neither well-established ICTs strategies, nor management information systems that provide consistent figures on their ICTs situation, Adam (2003). This implies that higher education institutions in Africa and in Ghana in particular need to work towards increasing the effective use of technology to support administrative activities including instituting rigorous ICT policies and strategies to manage its use. In their report on a study of ICT in higher education in Iran, Talebian, Mohammadi and Rezvanfar (2014) indicated that ICT also adds value to the process of learning and to the organization and management of learning institutions.

ICT resources can be used for various administrative activities. In their study Meenakumari and Krishnaveni (2011), found from a study that the highest use of technology was in the area of admission processes through electronic media and the least usage was regarding electronic mode of payment of fees by students. Also, Krishnavani [as cited in Toro \& Joshi 2012] highlighted the usage of ICT for administration in higher education institutions in terms of general administration, payroll and financial accounting, administration of students' data, personnel records maintenance and library system. Students administrative services using information technology application packages are numerous (Adebayo, 2013). As students are increasing in numbers, they are key to all activities in educational institutions. Higher education institutions need to secure and make information technology application packages available to administrators for the effective management of student activities and services. As rightly put by Meenakumari and Krishnaveni (2011), the increasing student population in higher education has accelerated the need for ICTs to process, store and retrieve data in a fast, systemic and accurate fashion. ICT can be used in various ways to provide student services. According to Toro and Joshi (2012), ICT provides student support services such as course outlines, digitally recorded classroom material, discussion groups, laboratory manuals and lab assignments, lecture notes, live lectures for later viewing and re-viewing, links to course specific websites, online tutorials, supplementary readings, and virtual office hours for teacher-student consultations.

\subsection{ICT Integration in Administration in HEIs}

The increasing population of students in higher education institutions has necessitated the need for ICT integration in administration in HEIs. Alam (2016), in his study of ICT in higher education in India, acknowledged that the increasing student population in higher education accelerated the need for ICTs to process, store and retrieve data in a fast, systemic and accurate fashion. ICT integration in administration in HEI are seen in various forms and stages. This is dependent on the ICT resources available, the skills and knowledge of staff in relation to ICT use, commitment of management as well as personnel attitude towards and or perceptions of the utilization of ICT. Various studies have been conducted in the area of ICT in relation to administration in Higher Education Institutions. Examples of available research such the one by as Adeoye, Oluwole, and Blessing, (2013) assessed the role of ICT as a change agent in HEI. Adebayo 
(2013) evaluated the impact of the application of ICT in administration in HEI, whilst Alam (2016) reviewed the use of ICT in higher education in general. This study focuses on administrators' perceptions on the role of ICT in their activities.

According to Oboegbulem and Ugwu (2013), ICT is used in managing student admissions, student and examination records, monitoring and evaluation of staff, planning for school activities, curriculum development, financial management and information dissemination as well as promoting communication between school units, parents, and principal administration. Krishnavani [as cited in Toro \& Joshi 2012] highlighted the usage of ICT for administration in Higher Education Institutions in terms of general administration, payroll and financial accounting, administration of students' data, personnel records maintenance and library system. When ICT use in the HEI is in the primary process, the technology is mainly used for daily administrative routines, presentations, assessment records, and budget preparation. ICT integration is at a higher level when HEI its use is in the secondary process whereby administrators additionally use the technology to manage information such as financial data and student registration, e-learning (use of blogs, social networks, student portals, and multimedia tools such as video) and online discussions. Mwalongo's (2011) study for instance, found out that administratively, ICT was used for preparing school announcements, reports, letters and student registration. The integration of ICT in administrative activities makes work in HEI effective. Similarly, Adebayo's (2013) study on the impact of ICT in administration in polytechnics in Nigeria found that information and communications technology enhances the quality of decision making in the administration of polytechnics. Reporting the findings of their study on the role of ICT in administration in Uganda, Juma, Raihan and Clement (2016) reiterated that ICT plays a major role in enhancing administrative efficiency and effectiveness through quick and accurate data organization and analyzation data, effective communication and knowledge sharing, gaining access to stakeholders, improving monitoring as well as tracking institutional resources. Using ICT in higher education administration is fundamentally about harnessing technology for better planning, setting standards, effecting change and monitoring results of the core functions of universities (Krishnaveni \& Meenakumari, 2010).

\subsection{Theoretical Framework of the Study}

This study draws on the Unified Theory of Acceptance and Use of Technology (UTAUT) to underpin the conclusions that will be derived from the findings. This is because the assumption is that administrators use of ICT for administrative activities is based on the importance, they attach to the role it plays in their work and the benefits accrued from its use. Also, once its use improves the effectiveness and efficiency of their work, they are more likely to accept, adopt, adapt and use technology. According to Taiwo and Downe (2013), the Unified Theory of Acceptance and Use of Technology (UTAUT) proposes that performance expectancy, effort expectancy, and social influence predict behavioral intention towards the acceptance of information technology. They also indicated that with UTAUT the facilitating conditions and behavioural intention predicts use behavior in the acceptance of information technology.

The theory was established on four theoretical constructs representing determinants of 'Use Behavior' or the 'Intention to Use', which play essential roles as surrogates of Technology Acceptance (Ahmad, 2014). The theoretical constructs are firstly performance expectancy, in that if the technology works favorably as expected it is likely to be used. The assumption therefore will be that administrators will increasingly use technology for their activities if it supports their work as expected. The second construct 'effort expectancy' equates the likelihood of use to the amount of effort needed to be able to use it. The third construct is the 'social influence,' which means that if it is socially acceptable, in that administrators agree to its benefits, it is more likely to be adapted and used. Finally, the construct of 'facilitating conditions,' implies that if administrators have the technical support to help them use technology, such as access to training available to give them the skills to facilitate technology use and the enabling environment through adequate facilities and policies showing management commitment, technology is more likely to be accepted and used by administrators.

\section{Problem statement}

As higher education institutions in Ghana work towards leading the integration of ICT in educational activities, it is significant that attention is paid to the adoption and adaption of ICT for administrative activities. ICT use improves management of education by ensuring more efficient administrative processes, which include human resource management, monitoring, evaluation and resources sharing. In order to support and manage the successful integration of technology in teaching and learning which constitute the main activities of HEIs, administrators need to "be equipped with knowledge, competencies and should have a deep understanding of educational and social dimension of ICT integration" (Adebayo, 2013). This means administrators need to have the right attitude towards the use of ICT, the skill to use it and ICT facilities made available and accessible to them. ICT use by administrators in HEI is critical as administrators are the pivot around which all HEI activities evolve. As perceptions have a strong influence on behavior this study sets out to explore the perceptions of administrators in line with the significance of ICT to their activities, the role it plays, its availability and accessibility to administrators of HEIs in Ghana.

This study was guided by the following research questions:

- In what ways do administrators of HEIs perceive the role of ICT in their activities?

- How do administrators use ICT to carry out their administrative activities?

- What kinds of information and communication technology tools and facilities are available to administrators in higher education institutions? 


\section{Methodology}

A case study design with a qualitative research paradigm approach was used to obtain in-depth information and analysis of administrators' perceptions on the role of ICT in administration and their use of it. Being a qualitative research, the aim was to get the opinions of administrators on the role ICT plays or could play in administrative activities in higher education institutions. Cases were taken from four randomly selected higher education institutions in Ghana. One institution was randomly selected from each of four main types of tertiary educational institutions namely; Universities, Technical Universities, Colleges of Education and Nurses Training Colleges. Administrators directly involved in the core administrative activities of the institutions were interviewed. Semi-structured interviews were used because they would help bring out new information, perceptions from the administrators' perspectives and enable flexible in-depth exploration of their understanding of the role of ICT in their duties. Purposive sampling was used to obtain the most accessible administrators. Six administrators were selected from the university, five from a technical university, four from a college of education and three from a nursing training college giving a total sample size of 18 . Analysis was done by categorizing data into themes related to the research questions.

\section{Results and Discussions}

\subsection{HEIs administrators' perception of the role of ICT in their activities}

The focus of the first research question was to find out administrators' perceptions of the importance of ICT and its role it plays in their day to day administrative activities. The emerging themes of the different perceptions were: Change of practice, efficiency and improvement in administrative activities and facilitation of data gathering and information dissemination.

\subsection{Change of Practice}

In relation to change of practice it was found that the use of ICT was significant as it had fundamentally changed the majority of administrative practices and procedures. Noteworthy was the change in how records are kept which were increasingly being digitalized. ICT has become part and parcel of all activities such as record keeping, communication and routine daily activities like writing letters and sending emails. ICT tools now form the thrust of all administrative duties in the institutions. Respondents mentioned: We use computers and other ICT tools every day; It forms an integral part of our work as administrators. Most of the respondents noted that presently their work cannot be done without ICT. A statement by one administrator that brings this up more succinctly: 'For me, I will say our work is dependent on these ICT tools and for that reason we use it all the time. This shows that ICT use has now become part and parcel of the daily duties of administrators as they have moved from manual to using technology. This finding on the digitalization of administrative activities is in line with results from a report on a survey of Swiss and German institutions of higher education on the digital future of higher education, which provides an indication that important developments have taken place in the field of administration in recent years. It was reported that many administrative processes have been digitalized in the pursuit of efficiency gains (Licka \& Gautschi, 2017). The main role ICT plays for administrators is it being a change agent to their administrative activities. The use of ICT changes the way they carry out their day to day activities.

\subsection{Efficiency and Improvement in Administrative Activities}

In terms of efficiency and improvement in administrative activities the administrators agreed that as technology is an essential part of their work it has played a critical role in impacting positively on the quality of their work. Most of the administrators shared similar statements as these: '... using ICT tools yields maximum satisfaction. It makes me want to work more.' The study also revealed that ICT tools improves administrators' level of work satisfaction although this was dependent on the efficiency of the tools and the skills of the administrator in ICT. A respondent noted; 'When ICT tools are working as they are supposed to, I enjoy using it and I think it blows my satisfaction up.' This supports one of the theoretical constructs of UTAUT of performance expectancy in that if the technology works favorably as expected, it is likely to be used.

Respondents also indicated that technology use in their administrative activities was important as it enhanced the quality of their work, saved office floor- space, saved time and enabled them to learn new things. An administrator reported, 'the use of technology in executing tasks helps me to save time and saves me a lot of physical effort'. This confirms the theoretical construct 'effort expectancy' which equates the likelihood of use to the amount of effort needed to be able to use it. Another administrator stated that 'ICT tools have also improved the quality of the work we do as administrators.' This implies that ICT plays the role of making the work of administrators efficient as they perform their administrative tasks such as record keeping, dissemination of information and report writing. Alam (2016) supports this finding as he indicated that ICT in administration of educational institutions plays a major role in efficient utilization of existing resources and simplifies the administrative tasks (like student, staff and general administration) by reducing the paper work and replacing the manual maintenance of record keeping to electronic record maintenance which helps in the easy retrieval of information.

The capacity of ICT in improving the work of administrators was also found in the study of Juma, Raihan, and Clement (2016), on the role of ICT in Higher educational administration in Uganda in which it was revealed that ICT facilitated adequate data storage, improving coordination of tasks and activities, making administrators more productive. The administrators perceived ICT playing the role of improving their work and making them more efficient. 


\section{How administrators use ICT to carry out their administrative activities}

The second research question sought to find out how administrators use ICT for their activities. Themes that reflect how ICT is used were captured in three main areas: the use for electronic database management, the use for office automation, and the use for preparation and presentation of reports.

\subsection{ICT Use for Electronic Data Management}

In the case of electronic database management, administrators use ICT to collect, store, and retrieve various kinds of data such as personnel and student records. Using ICT makes it easy for administrators to keep records. The administrators indicated: It helps us to quickly retrieve information easily and also helps us to gather and store data about our students and staff. In relation to data management another denoted; ICT tools makes information retrieval easier and also information stored on computers are safer and secured as compared to those in files. The administrators mentioned that they use ICT tools for data management because they derived varied benefits from using it. The benefits reported include storing and saving data, files being relatively simple and faster, and work moving faster with the use of ICT tools. Others noted: 'Keeping and retrieving data and document with the use of ICT tools is rela tively simple.'

The administrators similarly perceived the use of ICT as very important in the facilitation of data gathering and information dissemination. They noted that it made student and staff information readily available for retrieval and verification. Juma, Raihan, and Clement (2016), corroborate this finding as they noted from their study that ICT is relevant in facilitating effective and quick decision making, aiding analyzing data quickly and accurately, as well as facilitating information gathering and dissemination. This implies that the administrators use ICT to manage staff and student data. In a study by Krishnaveni, and Meenakumari (2010) on the use of ICT for information administration in higher education institutions, it was found out that it is mainly used in the areas of student and staff administration.

\subsection{ICT Use for Office Automation}

The use of ICT for office automation reflects its application in daily routine activities such as writing letters, memo, reports, and correspondences with stakeholders. The study revealed further that ICT is relevant in facilitating information gathering and dissemination. Almost all the administrators interviewed indicated that ICT use helps them gather information and distribute it to the concerned parties. One administrator said '... the use of technology helps us to send and exchange information. Example email etc' Being able to gather information electronically also helps in decision making. The administrators made statements like this: 'We are able to gather and capture information about staff and students with the help of the ICT tools for future use and for management in decision making.' Thus, the administrators use ICT for administrative activities related to staff and students as well as the dissemination of information. This affirms an OECD (2001) statement as cited in Krishnaveni and Meenakumari (2010) that in higher education institutions, ICT is used in the maintenance of student and staff records and for communication and document management.

\subsection{The Use of ICT in the Preparation and Presentation of Reports}

The third theme identified 'the use of ICT in the preparation and presentation of reports.' It was realized that the Internet was used to gather information to prepare reports whilst presentation applications were used to effectively present findings or reports. Some respondents noted that; Research for work is simple with the help of the computer. It helps navigate the Internet with ease.

All respondents of the interview mentioned that they use the technologies for administrative purposes such as communication; storage of correspondence and student information; retrieval of information; preparation of correspondence, minutes, speeches and reports; analyzing data for reporting; and for preparing presentations slides. They also said that ICT tools help in the systematic presentation of office work and for saving and storing office documents.

\section{Information and Communication Technology Tools and Facilities Available To Administrators in Higher Education Institutions}

The third research question basically looked at the different ICT tools and facilities available to administrators. The majority of administrators indicated that the main facilities available to administrators were Personal Computers with Internet connectivity, and other accessories such as printers, scanners, projectors and (mobile) telephones. These facilities were accessible to them as they were located within their offices. They said; 'We have printers, computer accessories, photocopier machine and scanners.' Administrators also indicated that the technology applications and tools available for their use in administration included the Internet, google calendar, google drive, drop box, spreadsheet, Microsoft office suite, TOPAZ and the Closed-Circuit Television (C.C.T.V) Camera.

\section{Conclusion}

Generally, the administrators indicated a positive perception on the role of ICT in relation to its use for higher educational administration. The role of ICT was seen as a change agent and a promoter of work efficiency. The perception of the administrators corroborated with the Unified Theory of Acceptance and Use of Technology theory which states that when performance expectancy, effort expectancy, and the facilitating conditions prevail administrators will be satisfied with using technology and will adopt it for their administrative activities. The administrators indicated their employment of different ICT tools in their work. 
In relation to how administrators use ICT, it could be concluded that it is used mainly for record keeping and retrieval of student and staff information. The use of technology facilitates administrative work and supports decision making. The three areas of use identified were electronic data management, office automation and report preparation. The use of ICT by the administrators was more in the secondary process whereby administrators use technology to support daily administrative activities and in managing information such as financial data, staff records and student registration.

\section{Recommendations and Implications for Practice}

Since administrators have a positive interest in the use of ICT for their activities, further training on ICT usage need to be provided to all administrators in order to ensure maximum productivity. Also, administrators need to be provided with technical support to address problems that may occur because of ICT usage. This is because as noted by Krishnaveni and Meenakumari (2010) using ICT in higher education administration is fundamentally about harnessing technology for better planning, setting standards, effecting change and monitoring results of the core functions of universities. An improvement in the skills of administrators in technology undoubtedly will result in improving the effectiveness of HEIs. Shaikh, and Khoja (2011) indicated that many studies suggest that suitable levels of investment, adequate training, good policy, careful planning, restructuring the teaching process, and a systematic approach are required when integrating ICT into the HES in order to achieve maximum educational benefits. It is therefore recommended that HEIs intentionally and strategically plan to improve the integration of ICT in the work of administrators. In order to do this HEIs need to continually create the awareness of the benefits of ICT use, adopt strategic plans committed to ICT integration, provide adequate training based on identified needs and as well provide the needed ICT tools and facilities.

\section{References}

i. Adam, L. (2003). Information and Communication Technologies in higher education in Africa: Initiatives and challenges JHEA/ RESA 1, (1), 195-221

ii. Adebayo, S. S. (2013). The impact of application of Information and Communications Technology (ICT) in the administration of polytechnics in Ogun state, Nigeria. International Journal of Students Research in Technology \& Management, 1(1), 505-515.

iii. Adeoye, Y.M., Oluwole, A.F. \& Blessing, L.O. (2013). Appraising the role of information communication technology (ICT) as a change a change agent in higher education in Nigeria. International Journal of Educational Administration and Policy Studies.5(8), 177-183

iv. Ahmad, M. I. (2014). Unified theory of acceptance and use of technology (UTAUT): A decade of validation and development Paper presented at Fourth International Conference on ICT in Our lives 2014, Alexandria University,Egypt

https:/ / www.researchgate.net/ publication/ 270282896 Unified Theory_of_Acceptance_and_Use_of_Technology_U TAUT A Decade of Validation and Development [accessed Nov $212019 \overline{]}$.

v. Alam, M. (2016) Use of ICT in higher education The International Journal of Indian Psychology 3, (4) 162-171 ISSN 2348-5396 (e) | ISSN: 2349-3429

vi. Bosu, R.S. (2008). Utilization of computer technology in public universities in Ghana: Implications for management. Journal of Educational Management 5, 1-14

vii. Juma, K. S., Raihan, M. A. \& Clement, C. K. (2016). Role of ICT in higher educational administration in Uganda World Journal of Educational Research 3(1) 1-10 ISSN 2375-9771 (Print) ISSN 2333-5998 (Online)

viii. Krishnaveni, R. \& Meenakumari, J. (2010). Usage of ICT for information administration in higher education institutions - A study International Journal of Environmental Science and Development 1, (3) 282- 286

ix. Licka, P. \& Gautschi, P. (2017). 2017 Survey: The digital future of higher education - What does it look like and how can it be shaped? Retrieved Nov. 2019 from https:/ / www.berinfor.ch/wp-content/ uploads/ 2018/ 01/ 2017 Survey-Berinfor-The_digital future_of higher_education.pdf

x. Maki, C. (2008). Information and Communication Technology for administration and management for secondary schools in Cyprus. Journal of Online Learning and Teaching, 4(3), 18-20.

xi. Meenakumari, J. \& Krishnaveni, R. (2011). Transforming higher educational institution administration through ICT International Journal of Advanced Computer Science and Applications, 2 (8), 46 -50

xii. Mohamedbhai, G. (2008). The effects of massification on higher Education in Africa. A Report on study of the effects of massification on higher education in Africa (Working Group on Higher Education (WGHE) of the Association for the Development of Education in Africa (ADEA)

xiii. Mwalongo, A. (2011). Teachers' perceptions about ICT for teaching, professional development, administration and personal use International Journal of Education and Development using Information and Communication Technology (IJEDICT), 7(3) 36-49.

xiv. Newman, E. (2016). Funding tertiary education in Ghana. Paper presented at the National Summit on Tertiary Education: November 2 - 4, 2016 Organisers: National Council for Tertiary Education, Ministry of Education \&Trust Africa, Senegal

xv. Onyije, L. E. \& Opara, J.A. (2013). Information and Communication Technologies (ICT): A panacea to achieving effective goals in institutional administration International Letters of Social and Humanistic Sciences Online: 2013-10-15 ISSN: 2300-2697, 12, 81-87 
xvi. Pyla, A. (2012). ICT as a change agent for higher education and society. International Conference on EGovernance and Cloud Computing Sevices (EGov '12) Proceedings published by International Journal of Computer Applications

xvii. Shaikh, Z. A., \& Khoja, S. A. (2011). Role of ICT in shaping the future of Pakistani higher education system TOJET: The Turkish Online Journal of Educational Technology 10 (1) 149 - 161

xviii. Taiwo, A. A. \& Downe, A. G. (2013) The theory of user acceptance and use of technology (UTAUT): A meta-analytic review of empirical findings. Journal of Theoretical and Applied Information Technology 49(1) 48-58

xix. Talebian, S., Mohammadi, M.H., \& Rezvanfar, A. (2014). Information and communication technology (ICT) in higher education: Advantages, disadvantages, conveniences and limitations of applying e-learning to agricultural students in Iran. Sogol Talebian / Procedia - Social and Behavioral Sciences 152, 300 - 305

xx. Toro, U. G. \& Joshi, M. (2012). ICT in Higher Education: Review of Literature from the Period 2004-2011, International Journal of Innovation, Management and Technology, 3 (1). 20 -23 